\title{
Study on the Moderating Effect of the Employee Psychological Empowerment on the Enterprise Employee Turnover Tendency: Taking Small and Middle Enterprises in Jinan as the Example
}

\author{
Kai Yao \\ School of Management, Fudan University, Shanghai 200433, China \\ E-mail: yaokai@fudan.edu.cn \\ Xiaoming Cui \\ School of Management, Fudan University, Shanghai 200433, China \\ E-mail: cuixm-1986@163.com
}

The research is supported by the State Natural Science Fund (No. 70872021), the State Social Science Fund (No. 06JA630017), the Humanities and Social Sciences Fund of Ministry of Education (No. 06JA630017), and Shanghai Municipal Humanities and Social Sciences Fund (No. 2005BJB003). (Sponsoring information)

\begin{abstract}
In the knowledge economy, the competition among enterprises is the competition about talents in the final analysis, and the intelligence capital becomes the key to build the core competitive advantage of enterprise. However, the abnormal turnover of employee will not only waste the human capital investment of enterprise, but also make against the implementation of the enterprise strategy and the construction of the culture. Based on the Price-Mueller (2000) model, this article adopts the definitions of the control variable, the structured variable, and the environment variable about employee turnover tendency, and creatively introduces the "employee psychological empowerment" as the Moderating variable to design and survey the questionnaire, and uses SPSS to regress in a stepwise way. The test result of the structure model by the empirical research shows that the fair allocation, the promotion opportunity, the monotonous work, the social internal support, and the exterior work chance are main factors to influence the employee turnover tendency, and the employee psychological empowerment could adjust enterprise employees' turnover tendency. Finally, this article suggests that enterprises should harmonize the relationship between the leader's authorization behavior and the employee's psychological empowerment to create healthy enterprise culture and promote effective talent encouragement.
\end{abstract}

Keywords: Employee psychological empowerment, Employee turnover, Price-Mueller model (2000)

\section{Introduction}

Private enterprise is very important for the national economic development of China, especially because of its flexible mechanism and big autonomy in management including employee invitation, salary system, and employee resign, private enterprise has big advantage to have good-quality talent resource, but some problems still are concealed in this advantage (Jiang, 2004). The normal flow of employee is normal and necessary for enterprise, but the actuality of employee flow in private enterprises of China is seriously unreasonable, and the general employee flow rate in private enterprises has achieved 50\% (Jiang, 2004, P.220), even more, which brings serious human resource replacement cost for enterprises, and impacts the sustainable development of enterprise. Therefore, to study the employee turnover phenomena of enterprise, especially study the influencing factors and Moderating factors of the employee turnover tendency could help enterprises to grasp employees' development trends, effectively predict and control employees' turnover behaviors, and reduce the risk of employee flow.

At present, for the research of the employee turnover, certain gap still exits in China and foreign countries. The development direction of the turnover research could provide new explanation variable for employee turnover tendency, specially could explore the decision-making process of the interactive influence of the employee turnover tendency (Price, J. L, 2001). But the factors with interactive influences are largely different, which decides that the western conclusions about employee turnover should not be copied. Domestic representative experts include Zhang Mian (2003) and Zhang Yichi (2005), and based on the Price-Mueller (2000) Model, they introduced many Moderating variables such as individual-organization matching (Zhang, 2005(3)), individual value view (Zhang, 2005(5)), promotion chance (Zhang, 2005(9)), and career satisfaction (Li, 2005), and studied the interactive influences of the factors deciding the employee turnover tendency, and obtained certain result, which could provide research methods to study the interactive influences of the factors in the process deciding 
the employee turnover tendency.

In the research of turnover, some experts put forward the opinion of "the contingency theory of employee turnover (Mobley W H, 1997, P.23 \& 7-240)", i.e. when considering the employee turnover, the environment variable of the organization should be emphasized. But as a rising concept, the "employee psychological empowerment" is very important to construct the organizational culture. At the same time, some researches indicate that the employee psychological empowerment and management validity (Spreitzer, 1995, 1997, 1999), the organizational commitment (Li, 2006 \& Kraimer, 1999), the employee innovational behavior (Janssen, 2005), and the work performance (Chen, 2005) all had significant influences, but according to Price-Mueller (2000)'s employee turnover model, these factors are key factors to impact the employee turnover, so it is necessary to study the function of the employee psychological empowerment in the employee turnover.

\section{Literature review}

\subsection{Theoretical review of employee psychological empowerment}

\subsubsection{Empowerment}

The empowerment is the usual behavior of enterprise, and especially in the development of modern enterprise, with the increase of enterprise scale, teacher's management extent is limited, and it is necessary to select part of power to realize the right sharing between superiors and juniors, which is the so-called empowerment (Robbins, 2005).

In past 20 years, the empowerment has been accepted by numerous organizational managers and utilized in their management practice, and the relative research of empowerment has been extensively concerned by organizational behaviorists ( $\mathrm{Li}, 2006, \mathrm{P} .99-106)$. However, because of the difference of the analysis view or key points, scholars have not achieved the common cognition for the definition of the empowerment for a long time. But in total, there are two trends for the research of empowerment in the academic circle (Hechanova M R M, 2006, P.72-78).

\section{(1) Relationship empowerment}

The relationship empowerment is also called by leader's empowerment (Wall, Cordery \& Clegg, 2002), and it is a superincumbent empowerment (Conger \& Kanungo, 1988). This mode regards the empowerment as a mode of participation, i.e. giving power and control force to employees in management (Ergeneli, 2007).

(2) Encouragement empowerment

The core content of encouragement empowerment is employee psychological empowerment (Liden, Wayne \& Sparrowe, 2000). This mode thinks that employees will have the feeling of empowerment when they are encouraged (Quinn \& Spreitzer, 1997).

In total, the empowerment is the combination of leader's empowerment behavior with his underling's psychological state (Lee and Koh, 2000).

\subsubsection{Employee psychological empowerment}

Conger \& Kanungo (1998) proposed another research angle of empowerment, i.e. the underlings' psychological state after they are empowered, and they called it as the "psychological empowerment".

Because psychological empowerment involves individual psychological cognition and experience, the meanings of empowerment must be different for different persons and different situations. Scholars have studies the attributive variables of psychological empowerment from different angles. From past relative empirical researches, the factors influencing individual psychological empowerment includes three aspects, (1) individual factors such as population statistical variable, personal character and interpretive styles, (2) factors of work character such as work autonomy, task feedback, (3) factors of team and organization such as team validity, social structural characteristics of the unity, and leader behavior (Ling, 2007).

\subsubsection{Research situation of employee psychological empowerment}

In existing researches, the research about psychological empowerment mainly includes the influences of organizational commitment and work performance. Concretely speaking, for example, Spreitzer $(1995,1997$ \& 1999 ) adopted the samples of senior mangers in 50 strongest enterprises of "Fortune" to study the influences of the employee psychological empowerment on employee work behavior and work performance. Jason (2005) found that the influencing dimension of psychological empowerment was significantly related with employees' innovational behavior. Chen (2005)'s research indicated that the psychological empowerment and the performance had the spiral relationship. Li Chaoping (2006) took the psychological empowerment as the agency 
variable, and researched the backside function mechanism of the revolutionary leadership on the employee satisfaction and the organizational commitment. Hepworth (2004) also found that the relationship of the psychological empowerment and the work invasion had part function of agency (Ling, 2007).

To sum up, though many researches about psychological empowerment studies many relative factors about employee turnover, but the function mechanism of employee psychological empowerment on the employee turnover has not been studied directly.

\subsection{Total design of the theoretical model}

To study the Moderating effect of the employee psychological empowerment on the employee turnover, the enterprise employee turnover model should be established first, and the Moderating variable of the "employee psychological empowerment" should be added in the employee turnover model to design and test the function mechanism of the model.

In domestic research about turnover, part of scholars combined western advanced theories with the concrete national situation of China from the empirical angle, such as the establishment and empirical research of Chinese IT enterprise employee flow cause model by Zhangmian (2001), the empirical research of the IT enterprise technical employee turnover intention route model by Zhangmian and Zhangde (2003), and the empirical research of the Price-Meuller (2000) model introducing "individual-organization matching", "individual value view", "promotion chance", and "career satisfaction" as the Moderating variables.

By using the usual method in Zhangmian $(2001,2003)$ and Zhang Yichi (2005)'s researches about turnover as references, based on the Price-Mueller (2000) turnover model, the function mechanism of "employee psychological empowerment" is established in this article.

The research of psychological empowerment mainly includes its influence on organizational commitment and work performance, but the organizational commitment and work performance are important factors to induce the employee turnover (David Buchanan, 2005). According to the researches about employee psychological empowerment (Spreitzer, 1999, Jason, 2005 \& Chen, 2005), large numerous of research results have been obtained after the employee psychological empowerment is introduced into the organizational behavior as the Moderating variable. The scholar Lingli (2007) provided the basic characters about the psychological empowerment when he summarized the research actuality of the employee psychological empowerment, and he pointed out that "in the researches taking the work attitude as the result viable, researchers found that the psychological empowerment was the complete agency variable among revolutionary leader and organizational commitment (Avolio, 2004 \& Aryee, 2006), LX and work satisfaction (Aryee, 2006), and empowerment atmosphere and work satisfaction (Seibert, 2004), i.e. the influence of the revolutionary leader behavior, LMX, and empowerment atmosphere on the organizational commitment or work satisfaction is completely realized by enhancing individual psychological empowerment level, and the psychological empowerment had part of agency function for the structure empowerment and work satisfaction. And some scholars surveyed the agency effect of different dimensions of psychological empowerment to the relative variables. For example, Liden (2000)'s researches showed that the dimension of meaning in the psychological empowerment had the function of agency between the work characteristic and work satisfaction with the organizational commitment, and the dimension of self-effect feeling had the function of agency between the work characteristic with the work satisfaction (Liden, 2000), and Li Chaoping (2006)'s research indicated that the revolutionary leaders' moral criterion could completely influence the employee satisfaction and organizational commitment by the dimension of meaning in the psychological empowerment, and the vision encouragement could completely influence the work satisfaction by the self-effect, and influence the organizational commitment by the meaning and the self-effect feeling." And the "organizational commitment", the "work satisfaction", and "LMX" proposed by Lingli (2007) are important variables in the research of turnover.

Therefore, using Zhangmian (2003) and Zhang Yichi (2005)'s usual methods in the research of employee turnover for references, the "employee psychological empowerment" is regarded as the Moderating variable in this article to study the Moderating effect in the employee turnover process.

\section{Research hypotheses}

According to above theoretical analysis, based on the Price-Mueller (2000) model and relative research literatures (Zhang, 2003 (4) \& Zhang, 2005 (5)), following research hypotheses are established.

\subsection{Control variable}

In the research about employee turnover, the variable of population statistics is usually researched as the important influencing factors. Based on former researches, many factors such as sex, age, and education have 
been proved as the important influencing factors of the employee turnover.

\subsection{Structured variable influencing the turnover}

In the research about employee turnover, the variable of population statistics is usually researched as the important influencing factors. Based on former researches, many factors such as sex, age, and education have been proved as the important influencing factors of the employee turnover.

Hypothesis 1a: Work autonomy is propitious to reduce the employee turnover tendency

Domestic experts have studied the relationship between the work autonomy and the employee turnover. Jean Marie Hiltrop (1999) pointed out that the work autonomy is the important factor to influence the employee turnover, and Smith (1996) thought that it was the fourth factor influencing the employee turnover that the company didn't endow employees' decision-making right, and Xia Yanling (2007) thought that the work autonomy would significantly influence the employee turnover. Therefore, the work autonomy is correlative to the employee turnover tendency.

Hypothesis 1b: Fair work allocation is propitious to reduce the employee turnover tendency

Domestic scholars, Liu Yong'an and Wangfang (2006), thought that employees' fair feeling, especially employees' fair feeling about salary could largely influence the employee turnover intention, and Xia Yanling (2007) thought that the justice of allocation could significantly explain the employee turnover tendency, and foreign expert Smith (1996) also thought that the unfair tendency in the allocation was the important factor to induce the employee turnover.

Hypothesis 1c: Fair organizational program is propitious to reduce the employee turnover tendency

About the research of the relationship between the fair organization program and the employee turnover tendency, domestic expert, Zhang Yichi (2005), thought that the fair organizational program could significantly explain the employee turnover whether it was the single variable or the Moderating variable, when he studied the Moderating effect of "individual-organization matching", "individual value view", "career satisfaction", and "promotion opportunity" in the decision-making process of the employee turnover tendency.

Hypothesis 1d: Salary (concealed) satisfaction is propitious to reduce the employee turnover tendency

There are many researches about the influences of the system salary on the employee turnover, and foreign experts, Kennedy, Ford (1999), and Hilltop (1999) all definitely pointed out that the income level was the important factor to influence the employee turnover. Domestic experts such as Xia Yanling (2007), Gu Jiajun (2007), Zhangmian (2003), Zhao Xiping (2003) and Liubing (2005) all studied both relationship, and thought that the both had the relativity.

But for the system salary, there are few researches about the concealed salary. Because of the characters of the concealed salary of enterprise, the relativity exists in the both.

Hypothesis 1e: Occupation growth is propitious to reduce the employee turnover tendency

For the research of the employee growth, Hilltop (1999) thought that the opportunity of training and ability promotion was the important factor to influence the employee turnover, and in the survey of the private enterprise in Hangzhou of Zhejiang, Xu Kenpeng (2006) found that the occupation growth was one of five main factors influencing the employee turnover.

Hypothesis 1f: Promotion opportunity is propitious to reduce the employee turnover tendency

The promotion opportunity is the demand that the employees achieve and realize themselves. Foreign experts Hanm and Gelesif (1995) thought that the performance the opportunity enhancement were important factor to influence the employee turnover, and Kennedy and Ford (1999) pointed out that the development of anticipated future would seriously influence the employees' decision of turnover, and Hilltop (1999) also thought that the opportunity of promotion could influence the employee turnover. Domestic experts, Xia Yanling (2007), Gu Xijun (2007), and Zhao Xiping (2003) also thought that the promotion opportunity was the important factor to influence the employee turnover.

Hypothesis 1g: Interior social support is propitious to reduce the employee turnover tendency

For the research about the influence of the interior social support on the employee turnover, Smith (1996) thought that the deficiency of the support of the senior layer of the company was the second largest factor influencing the employee turnover, and domestic experts, Zhangmian (2003) and Zhang Yichi (2005) also provided corresponding result, and Liu Yong'an also indicated that the interior human relationship was the important facto influencing the employee turnover. 
Hypothesis 1h: Work pressure is propitious to enhance the employee turnover tendency

For the relationship between the work pressure and the employee turnover tendency, Zhao Xiping (2003), Liu Yong'an (2006), Xia Yanling (2007) all thought that the employee turnover tendency was positively correlative with the work pressure, and the role pressure and the career development pressure were the most important influencing factors.

Hypothesis 1i: Monotonous work is propitious to enhance the employee turnover tendency

Hilltop (1999) pointed out that the work challenge was negatively correlated with the employee turnover tendency, and Hanm and Gelesif (1995) thought that the work complexity was the main factor to influence the employee turnover, and domestic expert, Xia Yanling (thought) that the monotonous work could significantly explain the employee turnover, and these both factors were positively correlated.

\subsection{Environment variable influencing the turnover}

Other work opportunities are an important variable in the Price-Mueller (2000) model, and it means the possibility estimation that employees could acquire the work opportunity in other organizations (Price, J. L, 2001).

Therefore, aiming at the environment variable, following hypothesis is proposed.

Hypothesis 2: Exterior work opportunities are apt to enhance the employee turnover tendency

In the Price-Mueller (2000) model, as two important variables, the opportunity and the family responsibility could significantly influence the employee turnover. And in the empirical analysis, Xia Yanling (2007) pointed out that the environment variable could significantly influence the employee turnover, and Hilltop (1999) also pointed out that the social economy was closely correlated with the employee turnover.

\subsection{Moderating variable influencing the turnover}

The employee turnover tendency will not certainly induce the turnover behavior, because in the process influencing employee turnover, except for the influences of control variable, structure variable, and environment variable, the influences of various Moderating variables, i.e. the interactive influences among factors could influence the employee turnover tendency under certain conditions (Mobley W H, 1977, P.23 7-240). On the contrary, when some employees have not the tendency of turnover or have lower turnover tendency, the Moderating variable may induce the turnover.

Traditionally, to study the influencing factors of employee turnover, most researches only considered the single influencing function of variable, not the interactive influences among variables.

Therefore, based on the Price-Mueller (2000) model, many scholars added various variables into the model to empirical test the model. In China, Zhang Yichi (2005) took the "individual-organizational matching (Zhang, 2005, P.37-41)" as the Moderating variable and found that the crossing item of the "blur role" and the "individual-organizational matching" and the "other work opportunities" and the "individual-organizational matching" have significant correlativity with the employee turnover tendency. And Zhang Yichi took the "individual value view (Zhang, 2005 (5))" as the Moderating variable and found two significant crossing items including the crossing item of the "role conflict" and the employee "individual value view" and the crossing item of the "skill diversity" and the "individual value view (Zhang, 2005 (9))". Taking the "promotion opportunity" as another Moderating variable, Zhang Yichi (2005) found three significant crossing items, i.e. the crossing item of "work autonomy" and "promotion opportunity", the crossing item of "fair allocation" and "promotion opportunity", and the crossing item of "superior support" and "promotion opportunity". Taking the "career satisfaction (Li, 2005 (11))" as the Moderating variable, Zhang Yichi (2005) found that the explanation of the employee career satisfaction to the employee turnover tendency could be enhanced about $3 \%$ significantly, and the crossing item of "career satisfaction" and "work autonomy" and the crossing item of "career satisfaction" and "superior support" could significantly influence the employee turnover tendency.

As discussed above, "the development direction of the employee turnover research is to discover new explanation variable for the employee turnover (Price, 2001)", especially to explore the Moderating effect of the Moderating variable for employees to make the decision of turnover, i.e. the crossing influence of the Moderating variable and the structure variable will influence the employee turnover.

Since the concept of "psychological empowerment" was proposed, the research about the psychological empowerment has been widely concerned by the management scholars. According to above literature summarization, following hypotheses are proposed. 
Hypothesis 3a: For the organization with high employee psychological empowerment, the work autonomy is propitious to reduce the employee turnover tendency more significantly.

Hypothesis $3 \mathrm{~b}$ : For the organization with high employee psychological empowerment, the fair allocation is propitious to reduce the employee turnover tendency more significantly.

Hypothesis 3c: For the organization with high employee psychological empowerment, the fair program is propitious to reduce the employee turnover tendency more significantly.

Hypothesis $3 \mathrm{~d}$ : For the organization with high employee psychological empowerment, the work pressure is apt to enhance the employee turnover tendency more significantly.

Hypothesis 3e: For the organization with high employee psychological empowerment, the salary (concealed) satisfaction is propitious to reduce the employee turnover tendency more significantly.

Hypothesis 3f: For the organization with high employee psychological empowerment, the occupation growth is propitious to reduce the employee turnover tendency more significantly.

Hypothesis 3g: For the organization with high employee psychological empowerment, the promotion opportunity is propitious to reduce the employee turnover tendency more significantly.

Hypothesis $3 \mathrm{~h}$ : For the organization with high employee psychological empowerment, the monotonous work is apt to enhance the employee turnover tendency more significantly.

Hypothesis 3i: For the organization with high employee psychological empowerment, the social interior support is propitious to reduce the employee turnover tendency more significantly.

Hypothesis 3j: For the organization with high employee psychological empowerment, the exterior work opportunity is propitious to enhance the employee turnover tendency more significantly.

Before empirical analysis, it is emphasized that this research has not considered the agency variable influencing the employee turnover tendency. In the Price-Mueller (2000) model, as the agency variables, the "work satisfaction" and the "organizational commitment" could influence the decision process of the employee turnover tendency. The focus of the research is the Moderating function of the employee psychological empowerment in the decision process of the turnover tendency, so this article doesn't consider the potential agency function of the work satisfaction and the organizational commitment between the attributive variable and the turnover tendency.

\section{Empirical analysis}

\subsection{Survey program and sample structure}

\subsubsection{Scaling}

This research adopts the locale interview and the questionnaire survey to compile the scaling, and the questionnaire includes three parts, and the first part is the individual basic information of employee, and the second part is the questionnaire of turnover cause (Price, 2001), and the third part is the questionnaire of the employee psychological empowerment (Spreitzer, 1995), and the questionnaire should be designed by the Likert's five-point scaling method.

To ensure the rationality of the questionnaire structure, the design of questionnaire adopts the focus group method, the interview method, and after the first-edition questionnaire was experimented in a small scale, the questionnaire was discussed and modified aiming at the problems. The survey is implemented after the experiment succeeded.

The SPSS 16.0 software is adopted to analyze the first-hand data collected by the questionnaire, and the concrete method includes the descriptive statistical analysis and relative analysis of variables, and the stepwise regression analysis method to validate above hypotheses.

\subsubsection{Sampling and surveying}

From July to Sep in 2008, the authors selected the private enterprise in Jinan of Shandong as the survey objects, and first primarily interviewed them, and then survey them by the questionnaire. To ensure the reliability of the survey result, the random sampling method is adopted to study the samples, so the result of questionnaire survey has more extensive representative characteristic. In this research, the amount of the questionnaire is 309 , and 279 of them are returned, and the return rate is $90.2 \%$. Because the measurements of questionnaire were respectively implemented in various departments, the quality of questionnaire could be ensured, and the validity of questionnaire is $90.2 \%$. The questionnaire adopts the anonymous mode, and the survey object of this research is 
only limited in formal employees of the sample enterprises.

\subsubsection{Reliability analysis of questionnaire}

This article adopts the coefficient of Cronbach $\alpha$ to test the reliability of questionnaire. According to the requirement of the psychological measurement, if the coefficient exceeds 0.8 , the survey scaling has highly interior coherence, and if the coefficient achieves 0.7 , the interior coherence of this scale could be accepted.

According to the characteristics of the questionnaire, the structure variable and the environment variable are taken out as one part to test, and the character of the employee psychological empowerment is taken out as the second part to test, and finally the whole questionnaire is tested.

By testing the questionnaire by the SPSS, the result is seen in Table 1.

Through Table 1, the reliability of questionnaire is reliable.

\subsection{Data analysis}

According to the empirical research framework, based on above research design, to test the explanation function of the structure variable and the environment variable to the employee turnover tendency, and the Moderating effect of the Moderating variable to the decision of the employee turnover tendency, this research adopts the SPSS 16.0 analysis software and the stepwise regression method to test the explanation ability of multiple explanation variables to the employee turnover tendency, and the regression analysis result is seen in Table 2.

According to the analysis in Table 2, the last list in Table 2 is the variance expansion index of variable (VIF) in the model 4, all VIFs are in 1 3 (Zhang, 2005, P.37-41, and Zhang thought that the value of VIF in 1 5 was acceptable) below 2, which indicates that the serious multiple-common-linearity doesn't exist among variables. In addition, the value of $\mathrm{D}$. W test (Durbin-Watson) value is 1.854 , which shows that the serious auto-correlation doesn't exist. Therefore, this research is meaningful, and the regression result is acceptable.

The control variables could explain $31 \%$ of the variable of turnover tendency $(F=17.149, p<0.1)$. In all control variables, the age $(\beta=-0.430, p<0.01)$ and the education $(\beta=0.347, \mathrm{p}<0.01)$ could strongly explain the turnover tendency, which indicates that the age is bigger, the turnover possibility is smaller, and the young employees' turnover is obvious, especially the employees (who were born in 1980s)' turnover should be concerned, and the education is significantly correlative with the employee turnover, which indicates that the education level is higher, the possibility of the turnover tendency is bigger, and the management of knowledge employee could be embodied.

To test the hypothesis 1 and the hypothesis 2, in the second step of the regression analysis, the structure-environment variable is put into the regression equation, and the regression result shows that the explanation ability of the model 2 to the variance of the employee turnover tendency could be significantly increased, $\Delta \mathrm{R}^{2}=41.6 \%$. And the fair allocation, the promotion opportunity, the monotonous work, and the social internal support in the structure variables could significantly explain the employee turnover tendency $(\beta=-0.225$, $\mathrm{p}<0.05 ; \beta=-0.405, \mathrm{p}<0.01 ; \beta=-0.210, \mathrm{p}<0.05 ; \beta=-0.212, \mathrm{p}<0.05)$, which supports the hypothesis $1 \mathrm{~b}$, the hypothesis $1 \mathrm{f}$, the hypothesis $1 \mathrm{~g}$ and the hypothesis 1 i, i.e. the justice of allocation could significantly reduce the employee turnover tendency, and the promotion opportunity is higher, the employee turnover tendency is lower, and the social interior support is higher, the employee turnover tendency is lower, and the work is more monotonous, the employee turnover tendency is higher. In these four factors, the explanation ability of the promotion opportunity to the employee turnover is most significant. The exterior work opportunity in the environment variable could significantly explain the employee turnover tendency $(\beta=0.432, p<0.01)$, and the hypothesis 2 is supported, which indicates that when employees apperceive exterior work opportunity, the possibility of turnover will be increased significantly.

To eliminate the possible influences on the turnover tendency before testing the Moderating effect, the authors put the employee psychological empowerment in the regression equation, and the result shows that this variable has not any explanation ability to the employee turnover tendency, that means the employee psychological empowerment could not influence the employee turnover tendency.

To test the hypothesis 3, the "employee psychological empowerment", the "structure variable", and the "environment variable" are first converted, and then the converted data are multiplied, and the product item of the employee psychological empowerment and the structure variable and the environment variable is put in the regression equation to establish the model 4 . The result indicates that for the organization with the strong degree of the employee psychological empowerment, the relationship that the salary (concealed) satisfaction could reduce the employee turnover tendency could be significantly strengthened, and the possibility that the 
monotonous work is apt to enhance the employee turnover tendency is significantly enhanced, and the fair program could actively reduce the employee turnover tendency.

\section{Conclusions and perspectives}

\subsection{Conclusions}

Based on the Price-Mueller (2000) model, by the empirical research method, using the domestic experts Zhangmian (2003) and Zhang Yichi (2004)'s usual methods in the research of the employee turnover, the questionnaire survey of the employee turnover is implemented in the article, and the software of SPSS 16.0 is used in this article to empirical analyze and study the structure variable and the environment variable influencing the employee turnover tendency, and the employee psychological empowerment (being the Moderating variable) is creatively introduced to study the Moderating effect of the employee psychological empowerment in the decision process of the employee turnover tendency.

According to the result of the regression analysis, as the single structured variables, the fair allocation, the promotion opportunity, the monotonous work, and the social interior support have close relationship with the employee turnover tendency. The environment variable, i.e. the exterior work opportunity, is positively correlated with the employee turnover tendency. After the Moderating variable, i.e. the employee psychological empowerment, is introduced, the "employee psychological empowerment", the "fair program", and the crossing item of "salary" and "promotion opportunity" could significantly explain the employee turnover tendency.

Aiming at the factors influencing the employee turnover tendency, the human resource management of enterprise could be strengthened with pertinence, and the prediction, cognition, and control of the employee turnover should be enhanced, which could help enterprises to establish the core human resource advantage.

\subsection{Limitations in this research}

Because of time and energy, there are many limitations in this research.

(1) Like other researches, the problem of common method variance is also a limitation of this article to some extent, and in this article, the error of the common method variance is not measured.

(2) The concrete organizational characteristics about the employee psychological empowerment have not been classified, and the Moderating function with pertinence has not been studied.

(3) The amount of the data survey sample needs to be further expanded, which could enhance the representative characteristic.

\subsection{Future research directions}

Except for the design of questionnaire and the selection of sample, the future research should perfect the design of the questionnaire to test the reliability and effect, actively expand the selection of sample, and make the research conclusion more representative and scientific. First, the research about the employee psychological empowerment should be studied more concretely.

(1) Aiming at different employee psychological empowerments, their respective Moderating effects on the employee turnover should be studied, and the difference should be compared and analyzed.

(2) Aiming at the concrete characteristics of the employee psychological empowerment, the Moderating effect should be further studied.

Second, the future research should consider the Moderating effect of other Moderating variables in the decision-making process of the employee turnover tendency, such as the "leader quality" and the "enterprise culture".

Third, the research about employee should be further reified, and this research has provided relative research information such as "the turnover and management of the employees who were born in 1980s" and "the knowledge employees' turnover and management".

(1) Taking the age as the background, for example, the research about the Moderating effect of the Moderating variable in the employees (who were born in 1980s)' decision of turnover tendency;

(2) Taking the post as the characteristic, for example, the research about the Moderating effect of the Moderating variable in the sales employees' decision of turnover tendency;

(3) Taking the educated degree as the object, for example, the research about the Moderating effect of the Moderating variable in the knowledge employees' decision of turnover tendency.

Finally, future researches should further emphasize the empirical research. 


\section{References}

Aryee S, Chen Z X. (2006). Leader-member exchange in a Chinese context: Antecedents, the mediating role of psychological empowerment and outcomes. Journal of Business Research. No.59(7). P.793-801.

Avolio B J, Zhu W C, Koh W, et al. (2004). Transformational leadership and organizational commitment: mediating role of psychological empowerment and moderating role of structural distance. Journal of Organizational Behavior. No.25(8). P.951-968.

Barroso Castro, Carmen, Villegas Perinan, Ma Mar, Casillas Bueno, Jose Carlos. (2008). Transformational leadership and followers' attitudes: the mediating role of psychological empowerment. International Journal of Human Resource Management. Oct 2008, Vol. 19 Issue 10. P.1842-1863.

Bhatnagar, Jyotsna. (2007). Predictors of organizational commitment in India: strategic HR roles, organizational learning capability and psychological empowerment. International Journal of Human Resource Management. Oct 2007, Vol. 18 Issue 10. P.1782-1811.

Chan, Yuen H. Taylor, Robert R. Markham, Scott. (2008). The Role of Subordinates' Trust in a Social Exchange-driven Psychological Empowerment Process. Journal of Managerial Issues. Winter 2008, Vol. 20 Issue 4. P.444-467.

Chen G, Klimoski R J. (2003). The impact of expectations on newcomer performance in teams as mediated by work characteristics, social exchanges, and empowerment. Academy of Management Journal. No.46(5). P.591-607.

Chen, Huei-Fang \& Chen, Yi-Ching. (2008). The Impact of Work Redesign and Psychological Empowerment on Organizational Commitment in a Changing Environment: An Example From Taiwan's State-Owned Enterprises. Public Personnel Management. Fall of 2008, Vol. 37 Issue 3. P.279-302.

Chen, Yongxia, Jia, Liangding \& Li, Chaoping et al. (2006). Reforming Leader, Psychological Empowerment, and Employee's Organizational Commitment: Empirical Research in China. Management World. No.1. P.96-105.

Cui, Jiaying. (2007). Primary Study on the Employee Psychological Empowerment. Human Resource Development of China. No.2.

David Buchanan \& Andrzej Huczynski. (2005). Organization Behavioristics. Beijing: Economic Management Press.

Ergeneli, Azize, Arı, Güler Sag `lam, Metin, Selin. (2007). Psychological empowerment and its relationship to trust in immediate managers. Journal of Business Research. Jan 2007, Vol. 60 Issue 1. P.41-49.

Gai, Yong. (2002). Organization Behavioristics. Ji'nan: Shandong People's Publishing House.

Gu, Jiajun \& Xie, Fenghua. (2007). An Empirical Study on the Reasons of Employee Turnover in Small and Medium Private Manufacturing Enterprises. Economic Survey. No.6.

Hall, Matthew. (2008). The effect of comprehensive performance measurement systems on role clarity, psychological empowerment and managerial performance. Accounting, Organizations \& Society. Feb 2008, Vol. 33 Issue 2/3. P.141-163.

Hechanova M R M, Alampay R B A, Franco E P. (2006). Psychological empowerment, job satisfaction and performance among Filipino service workers. Asian Journal of Social Psychology. No.9. P.72-78.

Huang, Liqun. (2004). Study on the Employee Turnover Problems in the Telecom Industry Group of Guangdong. Guangzhou: Ji'nan University.

Jha, Sumi S \& Nair, Shreekumar K. (2008). Influence of Locus of Control, Job Characteristics and Superior-Subordinate Relationship on Psychological Empowerment. Journal of Management Research (09725814). Dec 2008, Vol. 8 Issue 3. P.147-161.

Jiang, Xiuli \& Shi, Yan. (2004). Employee Flow Management. Ji'nan: Shandong People's Publishing House. P.220.

Li, Chaoping, Li, Xiaoxuan \& Shi, Kan et al. (2006). Psychological Empowerment: Measurement and Its Effect on Employee Work Attitude in China. Acta Psychologica Sinica. No.38(1). P.99-106.

Li, Chaoping, Tian, Bao \& Shi, Kan et al. (2006). Transformational Leadership and Employee Work Attitudes: The Mediating Effects of Multidimensional Psychological Empowerment. Acta Psychologica Sinica. No.38(2). P.297-307. 
Liden R C, Wayne S J, Sparrowe R T. (2000). An examination of the mediating role of psychological empowerment on the relations between the job, interpersonal relationships, and work outcome. Journal of Applied Psychology. No.85(3). P.407-416.

Ling, Li \& Lu, Changqin. (2007). Actuality of the Psychological Empowerment Research. Advances in Psychological Science. No.15.

Li, Shuling \& Zhang, Yichi. (2005). Study on the Modulation Effect of Career Satisfaction in Turnover Intention of Employee in China. Market \& Demographic Analysis. No.1.

Liu, Yong'an \& Wang, Fang. (2006). Study on the Factors Influencing Employee Turnover Intention. Enterprise Econmy. No.6.

Li, Zhen. (2004). Comparative Study the Employee Turnover Tendency in State and Private Systems. Wuhan: Huazhong University of Science and Technology.

Mao, Ren. (2006). Empirical Study on the Influence of the Welfare Satisfaction on the Employee Turnover Tendency in IT enterprises. Changsha: Hu'nan University.

Mobley W H. (1997). Intermediate link age in the relationship between job satisfaction and employee turnover. Journal of applied Psychology. No.62(2). P.23 \& 7-240.

Price, J. L. (2001). Reflections on the determinants of voluntary turnover. International Journal of Manpower.

Robbins. (2005). Organization Behavioristics. Beijing: China Renmin UP.

Seibert S E, Silver S R, Randolph W A. (2004). Taking empowerment to the next level: A multiple-level model of empowerment, performance, and satisfaction. Academy of Management Journal. No.47(3). P.332-349.

Sun, Weimin. (2006). Human Resource Management. Ji'nan: Shandong People's Publishing House.

Tang, Bo. (2004). Empirical Study on the Employee Turnover Tendency in Shiyan Telecom Enterprise. Wuhan: Huazhong University of Science and Technology.

Wang, Yiming. (2004). Measurement of Employee Quality. Ji'nan: Shandong People's Publishing House.

Xia, Yanling. (2007). The Turnover Influencing Factors Study in Small and Medium-sized Private Enterprises. Economy and Management. No.1.

Xu Huang, Kan Shi, Zhijie Zhang \& Yat LeeCheung. (2006). The impact of participative leadership behavior on psychological empowerment and organizational commitment in Chinese state-owned enterprises: the moderating role of organizational tenure. Asia Pacific Journal of Management. Sep 2006, Vol. 23 Issue 3. P.345-367.

Xu, Kunpeng. (2004). Study on the Knowledge Employee Turnover Tendency in Middle and Small Private Enterprises: Taking Zhengzhou of Henan as an Example. Ya'an: Sichuan Agricultural University.

Xu, Yihui. (2007). Empirical Study on the Knowledge Employee Turnover Model in China. Beijing: University of Science and Technology Beijing.

Zhang, Mian, Zhang, De \& Li, Shuzhuo. (2003). An Empirical Study on a Path Model of Turnover Intention among Technical Staff in IT Enterprises. Nankai Business Review. No.4.

Zhang, Yichi et al. (2005). Interaction Effects of Promotional Chances on Marketing Employee Turnover Intention. Chinese Journal of Management. No.5.

Zhang, Yichi et al. (2005). Moderating Effect of Individual Value in the Model for Employee Turnover Intention. Journal of China University of Geosciences (Social Sciences Edition). No.3.

Zhang, Yichi et al. (2005). Moderating Effects of P-P Fit in Turnover Intention Model: A Case of Foreign Pharmaceutical Companies in China. Nankai Business Review. No.3.

Zhao, Jinghua. (2002). Modern Management. Ji'nan: Shandong People's Publishing House.

Table 1. Questionnaire reliability table

\begin{tabular}{|c|c|}
\hline Name of scale & Cronbach's Alpha \\
\hline First part & 0.795 \\
\hline Second part & 0.707 \\
\hline Total questionnaire & 0.796 \\
\hline
\end{tabular}


Table 2. Result of regression analysis

\begin{tabular}{|c|c|c|c|c|c|c|}
\hline \multirow{2}{*}{\multicolumn{2}{|c|}{ Item }} & \multicolumn{4}{|c|}{ Turnover tendency } & \multirow{3}{*}{$\begin{array}{c}\text { Multicollinearity test VIF } \\
1.342 \\
\end{array}$} \\
\hline & & \multirow{2}{*}{$\begin{array}{c}\text { Model } 1 \\
-0.244 \\
\end{array}$} & \multirow{2}{*}{$\begin{array}{c}\text { Model } 2 \\
-0.476 \\
\end{array}$} & \multirow{2}{*}{$\begin{array}{c}\text { Model } 3 \\
-0.476 \\
\end{array}$} & \multirow{2}{*}{$\begin{array}{c}\text { Model } 4 \\
-0.268 \\
\end{array}$} & \\
\hline 1. & sex & & & & & \\
\hline 2. & age & $-0.430 * * *$ & -0.112 & -112 & -0.129 & 1.545 \\
\hline 3. & work age & -0.177 & 0.047 & 0.047 & 0.274 & 1.356 \\
\hline 4. & study experience & $0.347 * * *$ & -0.163 & -0.163 & $-0.192 * *$ & 1.743 \\
\hline 5. & married & -0.286 & 0.094 & 0.094 & 0.395 & 1.155 \\
\hline 6. & post & -0.573 & 0.045 & 0.045 & 0.259 & 1.634 \\
\hline 7. & work autonomy & & -0.153 & -0.153 & -0.184 & 1.252 \\
\hline 8. & fair allocation & & $-0.225 * *$ & $-0.225 * *$ & -0.25 & 2.754 \\
\hline 9. & fair program & & 0.154 & 0.154 & 0.218 & 2.456 \\
\hline 10. & work pressure & & -0.113 & -0.113 & -0.021 & 1.235 \\
\hline 11. & salary (hidden) & & -0.129 & -0.129 & $-0.251 * * *$ & 1.843 \\
\hline 12. & occupation growth & & -0.09 & -0.09 & -0.183 & 2.148 \\
\hline 13. & promotion chance & & $-0.405^{* * *}$ & $-0.405^{* * *}$ & $-0.326 * * *$ & 2.013 \\
\hline 14. & monotonous work & & $0.210 * *$ & $0.210^{* *}$ & $0.226^{*}$ & 1.254 \\
\hline 15. & social internal support & & $-0.212 * *$ & $-0.212 * *$ & $-0.022 * *$ & 1.332 \\
\hline 16. & exterior work chance & & $0.432 * * *$ & $0.432 * * *$ & $0.453 * * *$ & 1.436 \\
\hline 17. & PE factor & & & 0.095 & 0.175 & 1.354 \\
\hline 18. & PE* work autonomy & & & & -0.181 & 1.016 \\
\hline 19. & PE* fair allocation & & & & -0.048 & 1.254 \\
\hline 20. & PE* fair program & & & & $0.294 * *$ & 1.248 \\
\hline 21. & PE* work pressure & & & & -0.139 & 1.528 \\
\hline 22. & PE* salary (hidden) & & & & $-0.139 * * *$ & 1.451 \\
\hline 23. & PE*occupation growth & & & & -0.149 & 1.656 \\
\hline 24. & PE*promotion chance & & & & 0.127 & 2.006 \\
\hline 25. & PE*monotonous work & & & & $-0.219 * * *$ & 1.246 \\
\hline 26. & $\mathrm{PE}$ social internal support & & & & -0.11 & 1.152 \\
\hline 27. & PE*exterior work chance & & & & 0.22 & 1.553 \\
\hline & $\mathrm{R}^{2}$ & 0.31 & 0.726 & 0.726 & 0.809 & Durbin-Watson \\
\hline & $\mathrm{F}$ & $17.149 *$ & $12.823 * *$ & $12.823 * *$ & $15.648 * *$ & 1.854 \\
\hline & $\Delta \mathrm{R}^{2}$ & 0.31 & 0.366 & 0 & 0.074 & \\
\hline
\end{tabular}

Note: $*$ denotes $\mathrm{p}<0.1, * *$ denotes $\mathrm{p}<0.05, * * *$ denotes $\mathrm{p}<0.01$, and PE denotes the influencing factors of the employee psychological empowerment. 